\title{
Effect of body weight loss and normalization on blood pressure in overweight non-obese patients with stage 1 hypertension
}

\author{
Roberto Fogari, Annalisa Zoppi, Luca Corradi, Paola Preti, Amedeo Mugellini, Pierangelo Lazzari \\ and Giuseppe Derosa
}

We evaluated the effects of body weight (BW) loss on blood pressure (BP) in overweight non-obese patients with stage 1 hypertension. We enrolled 376 overweight (body mass index (BMI) $\geqslant 25$ and $<30 \mathrm{~kg} \mathrm{~m}^{-2}$ ) stage 1 hypertensive patients in this prospective 12-month trial. Each patient received tailored, low caloric dietary advice. After 6 months, patients with a BW reduction $<5 \%$ were excluded. Body weight, BMI, BP, fasting plasma glucose (FPG), fasting plasma insulin (FPI), leptin (pL), renin and aldosterone levels were evaluated at baseline and after 6 and 12 months. In 222 patients who completed the study, a mean weight reduction of $8.1 \mathrm{~kg}$ reduced systolic blood pressure (SBP) by $4.2 \mathrm{~mm} \mathrm{Hg}$ and diastolic blood pressure (DBP) by $3.3 \mathrm{~mm} \mathrm{Hg}(P<0.05)$, which was accompanied by a significant decrease in FPI, $\mathrm{pL}$ and aldosterone levels $(P<0.05)$. Larger SBP/DBP reductions were observed in 106 patients with normalized BMI $(-5 /-4.5 \mathrm{~mm} \mathrm{Hg}, P<0.01)$ compared with the 116 patients who did not become normalized $(-3.3 /-1.6 \mathrm{~mm} \mathrm{Hg}$ ). The former also presented with greater decreases in FPG, FPI, $\mathrm{pL}$, renin and aldosterone levels. Of the 106 patients who had normalized BMI, 52 also had normalized BP. Clinical and metabolic characteristics of these patients were similar to those of the 56 patients who did not have normalized BP. In overweight, mild hypertensive patients, weight loss was effective in reducing BP and in reversing some endocrinologic alterations associated with being overweight. Half of the patients who had normalized BMI also had normalized BP, which could indicate that these patients essentially did not have a form of hypertension but that these effects were instead secondary to being overweight.

Hypertension Research (2010) 33, 236-242; doi:10.1038/hr.2009.220; published online 15 January 2010

Keywords: blood pressure; overweight; weight-loss

\section{INTRODUCTION}

Excessive body weight (BW), in particular abdominal obesity, increases the risk for cardiovascular disease, stroke, type 2 diabetes, hypertension, lipoprotein disorders, osteoarthritis, certain types of cancers and total mortality. ${ }^{1-5}$ An escalating epidemic of overweight (body mass index (BMI) $\geqslant 25$ and $<30 \mathrm{~kg} \mathrm{~m}^{-2}$ ) and obesity (BMI $>30 \mathrm{~kg} \mathrm{~m}^{-2}$ ), is affecting both industrialized and many developing countries in the world, and constitutes a major public health problem. ${ }^{4,6,7}$ In particular, in the United States, the prevalence of obesity was estimated at $32 \%$ of the population. Being overweight was even more prevalent, representing $42 \%$ of men and $28 \%$ of women, of whom 34 and 39\%, respectively, had high blood pressure (BP). ${ }^{8,9}$ The coexistence of hypertension and excessive BW greatly enhances cardiovascular risk. ${ }^{2,10}$ Recent recommendations suggest the use of stratification tables to calculate the percentage of increased cardiovascular risk in patients with hypertension and excess BW or obesity. ${ }^{11}$ The mechanisms underlying hypertension in subjects with excessive BW remain to be elucidated; however, insulin resistance, sodium and fluid retention, adipocyte-mediated effects on angiotensin II, atrial natriuretic peptide levels and leptin-mediated enhancement of sympathetic activity may all have a role. ${ }^{12-14}$ The progression and persistence of obesity have been associated with a progressive alteration of the function and the structure of the vascular wall, including chronic inflammation, endothelial dysfunction, alteration of vascular tone and reactivity, proliferation of smooth muscle cells, neo-angiogenesis and altered patterns of blood flow regulation with both hypertensive and arteriosclerotic consequences. ${ }^{15-17}$ Some of the metabolic, endocrinologic and hemodynamic changes associated with obesity and hypertension are partially reversed by BW reduction, which decreases BP in overweight non-obese hypertensive patients. Numerous trials of hypertension treatment have shown that weight loss, whether alone or in combination with antihypertensive drugs, has a beneficial effect on BP control. ${ }^{18-21}$ Sharma et al. ${ }^{22}$ confirmed that BW loss is associated with significant reductions in $\mathrm{BP}$ and heart rate 
and may therefore have a role in the management of hypertension in overweight and obese patients. Some clinical studies have indicated that weight loss among overweight and obese subjects can reduce the risk of hypertension. ${ }^{23-26}$ Conversely, Winnicki et al..$^{27}$ showed that in stage 1 hypertensives followed for more than 6 years, the doseresponse relationship between BW loss and decrease in BP was not linear, irrespective of initial BW. Body weight loss $>13 \%$ of the initial weight did not elicit an additional BP decrease. Data on the antihypertensive efficacy of BW loss, specifically in overweight non-obese patients with untreated hypertension, however, are scarce. This population deserves special interest because (a) overweight is more prevalent than obesity, ${ }^{4,8,9}$ (b) overweight patients are more likely, than obese patients, to achieve and maintain BW reduction/normalization, and (c) overweight patients are less likely to present the structural alterations of the vascular wall that are commonly associated with the progression and persistence of obesity and may sustain elevated BP values. ${ }^{15-17}$ Given this background, the purpose of this study was to evaluate the effects of a 12-month dietary intervention, aimed at BW loss, on BP levels in overweight non-obese adults with never-treated stage 1 hypertension. Changes in some metabolic and endocrine parameters that are usually altered in obesity-related hypertension were also assessed.

\section{MATERIALS AND METHODS}

\section{Study design}

This was a prospective, open label, 12-month trial. The study protocol was approved by the institutional review board of the University of Pavia and was conducted in accordance with the Declaration of Helsinki and its amendments.

\section{Patients}

Caucasian overweight (BMI 25-29.9 $\mathrm{kg} \mathrm{m}^{-2}$ ), outpatients, males and females, aged 40-65 years, with never-treated stage 1 hypertension (systolic BP (SBP) $\geqslant 140$ and $<160 \mathrm{~mm} \mathrm{Hg}$ and/or diastolic (DBP) $\geqslant 90$ and $<100 \mathrm{~mm} \mathrm{Hg})^{28}$ were evaluated. Patients were excluded if they had a history of BW change $>3 \mathrm{~kg}$ within the previous 3 months, diabetes mellitus, secondary hypertension, myocardial infarction or stroke in the preceding 6 months, unstable angina, congestive heart failure, significant thyroid, pulmonary, renal or hepatic disease, gastrointestinal disorders, pregnancy or nursing, significant neurological or psychiatric disturbances (including alcohol or drug abuse) or use of anorexiant agents, laxatives, cyproheptadine, antidepressants, antiserotoninergics, phenothiazines, barbiturates, oral corticosteroids, antipsychotics or hormone replacement therapies. All patients provided written informed consent to participate.

\section{Treatment}

All subjects received dietary advice from a registered dietician. The dietary advice was tailored to each patient on the basis of 3-day food records. The recommended composition of the dietary regimen was as follows: carbohydrates, 50-60\%; proteins, $15-20 \%$; total fat, less than $30 \%$; saturated fats, less than $10 \%$; and cholesterol consumption, less than $300 \mathrm{mg}$ per day. Moreover, patients were advised to consume at least $250-300 \mathrm{~g}$ of fruits, $125-150 \mathrm{~g}$ of vegetables and $25-50 \mathrm{~g}$ of walnuts per day; they were also encouraged to consume $400 \mathrm{~g}$ of whole grains (legumes, rice, maize and wheat) daily and to increase their consumption of olive oil. The energy content of the diet was calculated from the patient's estimated basal metabolic rate multiplied by 1.3 to estimate the total daily energy expenditure for subjects with mild to moderate daily activity. From this, $600 \mathrm{kcal}$ per day was subtracted to give a mildly hypocaloric diet. The minimum caloric intake to be prescribed was $1200 \mathrm{kcal}$ per day. ${ }^{29}$

Compliance with the program was assessed by the attendance at meetings and evaluation of diet diaries. Patients consuming the control diet were given oral and written information about healthy food choices at baseline and at subsequent visits. Patients were followed up for 12 months and had monthly sessions with the dietitian and/or specialist physician during the study. Once a month, dietitians and/or specialists provided instructions on correct dietary intake-recording procedures as part of a behavior modification program and also used the patient food diaries for counseling.

To achieve a high external validity of the study, the nutritional therapy did not include any supplements or free-delivered food items, and subjects had to adopt the recommended diet strictly by themselves after intensive education.

After 2 months, patients who did not achieve a normal BMI $\left(<25 \mathrm{~kg} \mathrm{~m}^{-2}\right)$ and achieved a weight decrease $<2 \%$ were excluded, whereas patients who achieved a weight decrease between 2 and 5\% started treatment with orlistat, $120 \mathrm{mg}$ once daily, at dinner. After 4 months, patients who did not achieve a weight loss $\geqslant 5 \%$ and did not achieve a normal BMI doubled the orlistat dose (120 mg at lunch and $120 \mathrm{mg}$ at dinner). After 6 months, patients who achieved a weight loss $<5 \%$ without achieving a normal BMI were excluded.

We chose to administer orlistat because our previous study ${ }^{30}$ showed that orlistat was effective on anthropometric variables, such as BW and BMI, and that it was associated with a mild reduction in BP values; we also reported that orlistat and fluvastatin or orlistat and simvastatin seemed to have a synergistic effect on improving the lipid profile when used as combination therapy. ${ }^{31,32}$ There is also evidence that orlistat seems to be slightly more efficacious as an anti-obesity drug compared with sibutramine. ${ }^{33} \mathrm{~A}$ combination of orlistat and ezetimibe had more favorable effects on low-density lipoproteins (LDL-C) and small, dense low-density lipoprotein (sdLDL-C) levels in overweight and obese hypercholesterolemic patients than either drug alone. Furthermore, orlistat, alone or in combination with ezetimibe, improved several anthropometric and metabolic variables. ${ }^{34}$

\section{Efficacy and compliance assessment}

Before starting the study, all patients underwent an initial screening visit that included a medical history, physical examination, vital signs, 12-lead electrocardiogram, and measurements of height, BW, abdominal circumference, BMI, FPG, FPI, SBP, DBP, heart rate (HR), pL, renin and aldosterone levels. Body mass index, FPG, FPI, pL, renin and aldosterone levels were also assessed at 6 and 12 months. All plasmatic variables were determined after a 12-h overnight fast. Venous blood samples were drawn by a research nurse for all patients between 0800 and 0900 hours. We used plasma obtained by addition of $\mathrm{Na}_{2}$-EDTA $\left(1 \mathrm{mg} \mathrm{ml}^{-1}\right)$ and centrifuged at $3000 \mathrm{~g}$ for $15 \mathrm{~min}$ at $4{ }^{\circ} \mathrm{C}$. Immediately after centrifugation, the plasma samples were frozen and stored at $-80^{\circ} \mathrm{C}$ for $\leqslant 3$ months. All measurements were performed at a central laboratory.

Body mass index was calculated by the investigators as weight in kilograms divided by the square of height in meters. A biologist was responsible for the assays performed in the laboratory.

Plasma glucose was assayed using a glucose-oxidase method (GOD/PAP, Roche Diagnostics, Mannheim, Germany) with intra- and inter-assay CsV $<2 \%$ (European Diabetes Policy). Plasma insulin was assessed with Philadiaseph Insulin Radioimmunoassay (Pharmacia, Uppsala, Sweden) using a second antibody to separate the free and antibody-bound 125 I-insulin (intra- and inter-assay $\mathrm{CsV}, 4.6$ and $7.3 \%$, respectively). ${ }^{35}$

Plasma leptin concentrations were assessed in duplicate using commercially available ELISA kits (TiterZyme EIA Kit, Assay Designs, Ann Arbor, MI, USA). The intra- and inter-assay CsV was 4.5 and $6.5 \%$, respectively. ${ }^{36}$

Blood pressure measurements were obtained for each patient (right arm) in the seated position using a standard mercury sphygmomanometer (Korotkoff I and V; Erkameter 3000, ERKA, Bad Tolz, Germany) with a cuff of appropriate size. Measurements were always performed by the same investigator in the morning and after the subject had rested for $10 \mathrm{~min}$ in a quiet room. Three successive BP readings were obtained at 1-min intervals and averaged. Blood pressure recordings were performed by physicians not participating in the study to preserve study blindness of the experimenters. Heart rate was measured by pulse palpation over a 30-s period. To evaluate the tolerability assessment, all adverse events were recorded.

\section{Statistical analysis}

All data are presented as mean \pm s.d. A paired $t$-test was used to assess the changes in variables from baseline. Regression analysis of changes in BP parameters as a function of BMI reduction was used to determine whether 
SBP and/or DBP changes were related to the extent of BW loss. $P$-values $<0.05$ were considered significant. All analyses were performed using StatView 5.1 (SAS, Cary, NC, USA).

\section{RESULTS}

A total of 395 patients were screened for eligibility; 376 fulfilled the inclusion/exclusion criteria and were enrolled. Of these patients, 222 (59\%) completed the study. A total of 154 discontinued the study, 139 (37\%) due to insufficient BW reduction and 15 for other reasons. Table 1 shows the clinical and demographic characteristics of the study population at baseline. No major differences were detected between the patients who completed the study and those who dropped-out due to insufficient BW reduction.

The effects of BW loss on the hemodynamic, metabolic and endocrine characteristics of the patients who completed the study are presented in Table 2. Over the 12-month period during which the trial was conducted, BW decreased by a mean of $8.1 \mathrm{~kg}(-10 \%$, $P<0.01$ vs. baseline), BMI decreased by $2.8 \mathrm{~kg} \mathrm{~m}^{-2}(-10.1 \%$, $P<0.01$ vs. baseline), and abdominal circumference decreased by $3.5 \mathrm{~cm}$ ( $-3.6 \%, P<0.05$ vs. baseline). The corresponding reduction in SBP was $-4.2 \mathrm{~mm} \mathrm{Hg}(-2.8 \%, P<0.01 v s$. baseline $)$, whereas the mean decrease in DBP was $-3.3 \mathrm{~mm} \mathrm{Hg}(-3.5 \%, P<0.01$ vs. baseline). Significant reductions in FPI $\left(-1 \mathrm{Uml}^{-1},-11.7 \%\right), \mathrm{pL}$ $\left(-7 \mathrm{ng} \mathrm{ml}^{-1},-26.3 \%\right)$ and aldosterone levels $\left(-5 \mathrm{ngl}^{-1},-10.4 \%\right)$ were also observed (all $P<0.05$ vs. baseline).

Of the 222 patients who completed the study, 106 (47\%) achieved a normal BMI (BMI <25). Although the remaining 116 patients significantly reduced their BMI, it did not reach normal levels. Table 3 shows the effects of BW loss on the hemodynamic, metabolic and endocrine characteristics of the patients who completed the study according to the results obtained (that is, if they were able to normalize BMI). Aside from the greater reduction in BW (-11.9 vs. $-7.9 \%)$, BMI (-12.9 vs. $-7.6 \%)$ and abdominal circumference $(-4.1$ vs. $2.9 \%$ ), larger BP reductions were observed in patients who achieved normal BMI than in those who did not in both SBP $(-5 \mathrm{~mm} \mathrm{Hg}$, $-3.4 \%$ vs. $-3.3 \mathrm{~mm} \mathrm{Hg},-2.2 \%)$ and DBP $(-4.5 \mathrm{~mm} \mathrm{Hg},-4.7 \%$ vs. $-1.6 \mathrm{~mm} \mathrm{Hg},-1.6 \%)$. Subjects who normalized their BMI also presented a greater decrease in FPG (-3.1 vs. -1.5$)$, FPI (-19.7 vs.
$-5.9 \%)$, plasma renin $(-14.8$ vs. $-6.5 \%)$, plasma aldosterone $(-13.5$ vs. $-8.3 \%)$ and $\mathrm{pL}(-29.9$ vs. $-22.2 \%)$ levels.

Of the 106 patients who normalized their BMI, 52 also achieved normal BP levels $(<140 / 90 \mathrm{~mm} \mathrm{Hg}$ ), whereas 54 did not reach normal $\mathrm{BP}$ values. Table 4 shows the effect of weight loss on the hemodynamic, metabolic and endocrine characteristics of the patients who normalized their BMI as a function of whether they normalized their BP levels. With the expected exception of SBP and DBP values, no significant difference was found between the two groups for the other parameters, including BW, FPI, pL, renin and aldosterone levels.

Figure 1 shows the relationship between BMI and DBP reduction in patients who achieved normal BP levels compared with those who did not. In both groups, a highly significant positive correlation was found between BMI and DBP decrease, although at varying strengths.

\section{DISCUSSION}

The objective of this study was to evaluate the effects of a 12-month dietary intervention focusing on BW loss, on BP levels in overweight,

Table 2 Effect of weight loss on hemodynamic, metabolic, and endocrine characteristics in the patients who completed the study

\begin{tabular}{|c|c|c|c|}
\hline & Baseline & 6 months & 12 months \\
\hline $\mathrm{BMI}\left(\mathrm{kg} \mathrm{m}^{-2}\right)$ & $27.6 \pm 1.2$ & $25.7 \pm 0.8^{*}$ & $24.8 \pm 0.7^{* *}$ \\
\hline Weight (kg) & $80.2 \pm 5.4$ & $75.6 \pm 4.7^{*}$ & $72.1 \pm 3.6^{* *}$ \\
\hline Abd. Circ. (cm) & $95.7 \pm 6.7$ & $93.6 \pm 5.9$ & $92.2 \pm 3.9^{*}$ \\
\hline $\mathrm{SBP}(\mathrm{mm} \mathrm{Hg})$ & $146.8 \pm 6.3$ & $143.8 \pm 5.7$ & $142.6 \pm 5.4^{* *}$ \\
\hline $\mathrm{DBP}(\mathrm{mm} \mathrm{Hg})$ & $94.4 \pm 2.0$ & $92.5 \pm 1.6^{*}$ & $91.1 \pm 1.4^{* *}$ \\
\hline Heart rate (b.p.m.) & $74.1 \pm 6.1$ & $73.8 \pm 5.8$ & $73.5 \pm 5.7$ \\
\hline $\mathrm{FPG}\left(\mathrm{mg} 100 \mathrm{ml}^{-1}\right)$ & $90.7 \pm 6.8$ & $88.8 \pm 6.3$ & $88.2 \pm 6.1$ \\
\hline $\mathrm{FPI}\left(\mu \mathrm{U} \mathrm{ml}^{-1}\right)$ & $8.5 \pm 3.3$ & $7.9 \pm 3.2$ & $7.5 \pm 2.9 *$ \\
\hline $\operatorname{Renin}\left(\left.n g\right|^{-1}\right.$ ) & $4.6 \pm 2.5$ & $4.4 \pm 2.4$ & $4.1 \pm 2.3$ \\
\hline Aldosterone $\left(\left.\mathrm{ng}\right|^{-1}\right)$ & $48.1 \pm 10.4$ & $45.1 \pm 10.1$ & $43.1 \pm 8.2^{*}$ \\
\hline Leptin (ng ml-1) & $26.6 \pm 6.5$ & $22.9 \pm 6.1$ & $19.6 \pm 5.5^{*}$ \\
\hline
\end{tabular}

Abbreviations: Abd. Circ., abdominal circumference; BMI, body mass index; b.p.m., beats per minute; DBP, diastolic blood pressure; FPG, fasting plasma glucose; FPI, fasting plasma insulin; SBP, systolic blood pressure.

Data are expressed mean \pm s.d.

${ }^{*} P<0.05$ vs. baseline; ${ }^{* *} P<0.01$ vs. baseline.

Table 1 Demographic and clinical characteristics of patients at baseline

\begin{tabular}{|c|c|c|c|c|}
\hline & All patients & Completed the study & Withdrawals for insufficient $B W$ reduction & $\mathrm{P}$ \\
\hline No of patients & 376 & 222 & 139 & \\
\hline $\operatorname{Sex}(M / F)$ & $178 / 198$ & $105 / 117$ & $73 / 81$ & \\
\hline Age (years) & $54.8 \pm 8.8$ & $55.1 \pm 9.4$ & $54.5 \pm 8.2$ & NS \\
\hline Hyp. Dur. (years) & $1.9 \pm 1.2$ & $1.8 \pm 1.1$ & $1.9 \pm 1.2$ & NS \\
\hline $\mathrm{BMI}\left(\mathrm{kg} \mathrm{m}^{-2}\right)$ & $27.7 \pm 1.3$ & $27.6 \pm 1.2$ & $27.8 \pm 1.4$ & NS \\
\hline Height (m) & $1.70 \pm 0.06$ & $1.70 \pm 0.06$ & $1.71 \pm 0.05$ & NS \\
\hline Weight (kg) & $80.5 \pm 7.5$ & $80.2 \pm 5.4$ & $80.7 \pm 8.1$ & NS \\
\hline Abd. Circ. (cm) & $95.8 \pm 7.0$ & $95.7 \pm 6.7$ & $96.0 \pm 7.4$ & NS \\
\hline $\mathrm{SBP}(\mathrm{mm} \mathrm{Hg})$ & $147.8 \pm 6.3$ & $146.8 \pm 6.3$ & $148.1 \pm 6.2$ & NS \\
\hline $\mathrm{DBP}(\mathrm{mm} \mathrm{Hg})$ & $94.4 \pm 2.1$ & $94.4 \pm 2.0$ & $94.5 \pm 2.1$ & NS \\
\hline Heart rate (b.p.m.) & $74.4 \pm 6.2$ & $74.1 \pm 6.1$ & $74.7 \pm 6.3$ & NS \\
\hline FPG (mg $100 \mathrm{ml}^{-1}$ ) & $90.2 \pm 6.6$ & $90.7 \pm 6.8$ & $89.8 \pm 6.4$ & NS \\
\hline $\mathrm{FPI}\left(\mu \cup \mathrm{ml}^{-1}\right)$ & $8.3 \pm 3.1$ & $8.5 \pm 3.3$ & $8.2 \pm 2.9$ & NS \\
\hline Renin (ng $\left.\right|^{-1}$ ) & $4.6 \pm 2.6$ & $4.6 \pm 2.5$ & $4.5 \pm 2.6$ & NS \\
\hline Aldosterone (ng $\left.\right|^{-1}$ ) & $47.3 \pm 9.8$ & $48.1 \pm 10.4$ & $46.6 \pm 9.2$ & NS \\
\hline Leptin (ng ml-1) & $26.5 \pm 6.1$ & $26.6 \pm 6.5$ & $24.3 \pm 6.7$ & NS \\
\hline
\end{tabular}

Abbreviations: Abd. Circ., abdominal circumference; BMI, body mass index; BW, Body Weight; b.p.m., beats per minute; DBP, diastolic blood pressure; FPG, fasting plasma glucose; FPI, fasting plasma insulin; Hyp. Dur., Hypertension Duration; NS, not significant; SBP, systolic blood pressure.

Data are presented as mean \pm s.d. 
Table 3 Effect of treatment on hemodynamic, metabolic and endocrine characteristics in the patients who completed the study

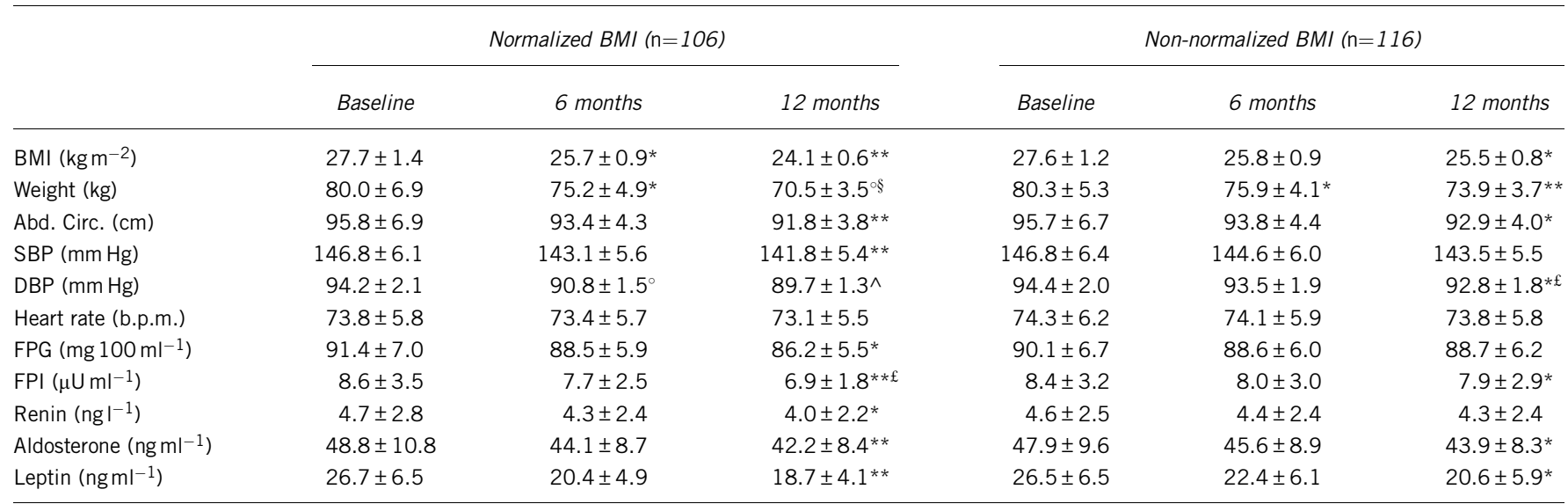

Abbreviations: Abd. Circ., abdominal circumference; BMI, body mass index; b.p.m., beats per minute; DBP, diastolic blood pressure; FPG, fasting plasma glucose; FPI, fasting plasma insulin; SBP, systolic blood pressure.

Dystolic blood pressure.

${ }^{\star} P<0.05$ vs. baseline; ${ }^{* *} P<0.01$ vs. baseline; ${ }^{\circledR} P<0.05$ vs. Nn BMI; ${ }^{\circ} P<0.01$ vs. baseline; ${ }^{\wedge} P<0.0001$ vs. baseline; ${ }^{£} P<0.01$ vs. 12 months.

Table 4 Effect of treatment on hemodynamic, metabolic, and endocrine characteristics in the patients who normalized BMI

\begin{tabular}{|c|c|c|c|c|c|c|}
\hline & \multicolumn{3}{|c|}{ Patients who normalized $B M I$ and $B P(\mathrm{n}=52)$} & \multicolumn{3}{|c|}{ Patients who normalized BMI but not $B P(\mathrm{n}=54)$} \\
\hline & Baseline & 6 months & 12 months & Baseline & 6 months & 12 months \\
\hline $\mathrm{BMI}\left(\mathrm{kg} \mathrm{m}^{-2}\right)$ & $27.6 \pm 1.5$ & $25.6 \pm 0.9$ & $24.1 \pm 0.6$ & $27.7 \pm 1.2$ & $25.9 \pm 1.0$ & $24.1 \pm 0.6$ \\
\hline Weight (kg) & $79.8 \pm 5.9$ & $74.1 \pm 4.6$ & $69.6 \pm 3.3$ & $80.1 \pm 7.1$ & $74.6 \pm 5.1$ & $70.3 \pm 3.7$ \\
\hline Abd. Circ. $(\mathrm{cm})$ & $96.0 \pm 7.1$ & $93.3 \pm 4.4$ & $91.8 \pm 4.0$ & $95.8 \pm 6.9$ & $93.5 \pm 4.5$ & $91.9 \pm 4.1$ \\
\hline $\mathrm{SBP}(\mathrm{mm} \mathrm{Hg})$ & $146.9 \pm 3.7$ & $141.6 \pm 3.2$ & $138.4 \pm 2.9^{\circ}$ & $146.8 \pm 3.9$ & $144.5 \pm 3.7$ & $143.6 \pm 3.6 *$ \\
\hline $\mathrm{DBP}(\mathrm{mm} \mathrm{Hg})$ & $94.0 \pm 1.9$ & $89.2 \pm 1.4^{\circ}$ & $87.1 \pm 1.3^{\circ}$ & $94.3 \pm 2.1$ & $92.2 \pm 1.7$ & $91.9 \pm 1.1$ * \\
\hline Heart rate (b.p.m.) & $73.2 \pm 5.1$ & $73.0 \pm 4.9$ & $72.8 \pm 4.7$ & $74.3 \pm 5.5$ & $73.8 \pm 5.2$ & $73.3 \pm 5.1$ \\
\hline $\mathrm{FPG}\left(\mathrm{mg} 100 \mathrm{ml}^{-1}\right)$ & $91.3 \pm 6.9$ & $88.4 \pm 5.7$ & $86.1 \pm 4.8$ & $91.5 \pm 7.0$ & $88.7 \pm 6.0$ & $86.2 \pm 4.8$ \\
\hline $\mathrm{FPI}\left(\mu \mathrm{Uml^{-1 }}\right)$ & $8.5 \pm 3.4$ & $7.6 \pm 2.5$ & $6.8 \pm 1.7$ & $8.7 \pm 3.6$ & $7.8 \pm 2.6$ & $6.9 \pm 2.0$ \\
\hline Renin (ng $\left.\left.\right|^{-1}\right)$ & $4.5 \pm 2.6$ & $4.3 \pm 2.4$ & $4.0 \pm 2.2$ & $4.8 \pm 3.0$ & $4.4 \pm 2.5$ & $4.0 \pm 2.2$ \\
\hline Aldosterone (ng ml ${ }^{-1}$ ) & $48.7 \pm 10.8$ & $46.4 \pm 9.2$ & $42.6 \pm 8.5$ & $48.9 \pm 10.9$ & $46.8 \pm 9.5$ & $43.1 \pm 8.6$ \\
\hline Leptin (ng ml-1) & $26.7 \pm 6.5$ & $20.2 \pm 4.8$ & $18.5 \pm 3.9$ & $26.7 \pm 6.4$ & $20.6 \pm 5.1$ & $18.9 \pm 4.2$ \\
\hline
\end{tabular}

Abbreviations: Abd. Circ., abdominal circumference; BMI, body mass index; b.p.m., beats per minute; DBP, diastolic blood pressure; FPG, fasting plasma glucose; FPI, fasting plasma insulin; Hyp. Dur., hypertension duration; nBP, normalized blood pressure; NnBP, non-normalized blood pressure; SBP, systolic blood pressure.

Data are expressed as mean \pm s.d.

${ }^{*} P<0.05$ vs. normalized $\mathrm{BP} ;{ }^{\circ} P<0.05$ vs. baseline.

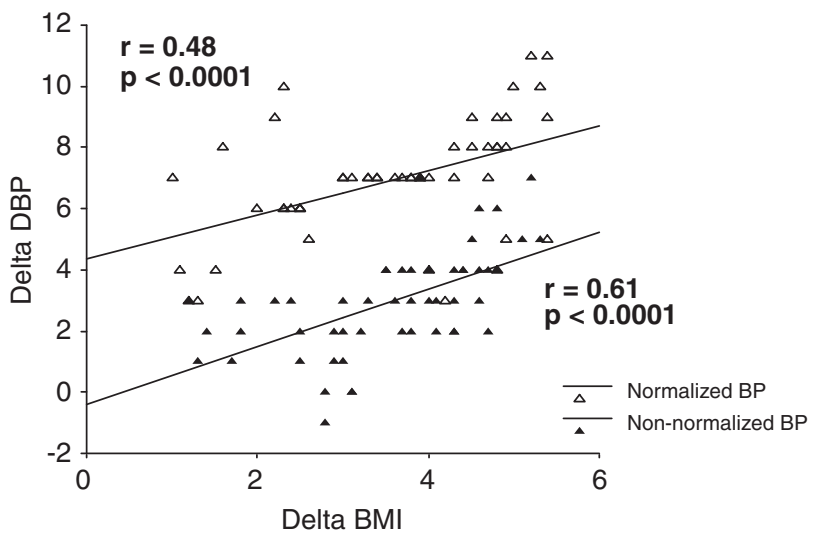

Figure 1 Relationship between $\mathrm{BMI}$ and DBP reduction in patients who normalized their BP $(\triangle)$ levels compared with those who did not normalized $\mathrm{BP}(\mathbf{\Delta})$. non-obese adults with never-treated, stage 1 hypertension. Of the 376 patients enrolled, 139 (37\%) were disqualified due to insufficient BW decrease. Their demographic, clinical, metabolic and endocrine characteristics were quite similar to those of patients who completed the study, indicating that the inability to follow the diet was the main factor responsible for the insufficient weight reduction. This confirms that weight loss is difficult to achieve and sustain, and long-term maintenance of adequate weight loss is achieved only in a proportion of overweight patients. ${ }^{26,37}$

In the patients who completed the study, a mean weight loss of $8.1 \mathrm{~kg}(P<0.01 v s$. baseline $)$, along with a BMI reduction of $10 \%$ and an abdominal circumference decrease of $3.6 \%$, produced a reduction of $4.2 \mathrm{~mm} \mathrm{Hg}$ in SBP $(-2.8 \%, P<0.01$ vs. baseline $)$ and of $3.3 \mathrm{~mm} \mathrm{Hg}$ in DBP $(-3 \%, P<0.01$ vs. baseline). Systolic and diastolic reductions in blood pressure were -0.52 and $-0.41 \mathrm{~mm} \mathrm{Hg}$, respectively, when expressed per kilogram of weight loss. These reductions were similar to those observed by other authors, ${ }^{38-41}$ although lower than those 
reported by some meta-analyses. ${ }^{42-44}$ This might reflect differences in the study design and population. An element of novelty of our study was represented by the results regarding patients who were able to normalize their BMI, because, to our knowledge, no other study has specifically evaluated the effects of BW normalization in overweight non-obese hypertensive patients. In this study, patients who normalized their BMI (47\% of the patients who completed the study) had greater SBP and an even greater decrease in DBP $(-5 /-4.5 \mathrm{~mm} \mathrm{Hg})$ compared with those who, although significantly lowering their BW, did not normalize their BMI $(-3.3 /-1.6 \mathrm{~mm} \mathrm{Hg}$ for SBP/DBP). In these patients, failure to normalize their BMI was exclusively due to less rigorous adherence to the diet, as no difference in age, gender or other baseline characteristics was found between the groups.

In this study, BW reduction, besides lowering BP levels, was accompanied by a significant decrease in plasma insulin $(-11.7 \%)$, aldosterone $(-10.4 \%)$ and leptin levels $(-26.3 \%)$. Interestingly, these changes were more significant $(-19.7 \%$ insulin, $-13.5 \%$ aldosterone and $-29.9 \%$ leptin decrease) in patients who normalized their BMI, which also presented a significant reduction in FPG $(-3.1 \%)$ and renin levels $(-14.8 \%)$. The decrease in fasting plasma glucose and insulin levels observed in this study suggests an improved insulin sensitivity, which may be partly responsible for the fall in BP observed with weight loss in our overweight non-obese hypertensive patients. It is well known that excess BW is associated with insulin resistance and hyperinsulinemia, which in turn may promote hypertension through multiple mechanisms. ${ }^{45-47}$

The renin-angiotensin-aldosterone system (RAAS) is overactivated in overweight obese hypertensive subjects, and plasma renin activity (PRA) and aldosterone concentrations are higher than those in lean subjects. ${ }^{48-53}$ Activation of the RAAS increases sodium retention and peripheral resistance, thereby contributing to obesity hypertension. Locally produced angiotensin II, arising from adipose tissue itself, and adipocyte-derived proteins modulating aldosterone secretion ${ }^{51,54,55}$ may also have a significant etiological role. Body weight reduction has been shown to reduce PRA and aldosterone levels in obese hypertensive subjects, possibly by decreasing sympathetic nerve activity. ${ }^{48,56-58}$ Reduction in sympathetic nervous system (SNS) activity has been found to accompany caloric restriction in animals and humans, ${ }^{59,60}$ as the SNS and renal nerves are major factors in modulating renin release. It is therefore possible that the changes in PRA reflect diminished SNS activity. Consistent with several studies, we found that a reduction in BW was accompanied by a significant reduction in aldosterone levels and, only in patients who normalized their BMI, in plasma renin, which may have contributed to the observed reduction of BP values.

It has become evident that adipose tissue, far from being an inert organ for storing excess calories, synthesizes and secretes a number of metabolically active molecules, including $\mathrm{pL}$, adiponectin, resistin, tumor necrosis factor- $\alpha$, interleukin- 6 and plasminogen activator inhibitor-1, which, besides exerting autocrine effects on the adipose cells, are involved in cardiovascular regulation. ${ }^{15-17,61,62}$ Among the adipose tissue-derived substances, $\mathrm{pL}$ has multiple actions that are potentially relevant not only for the control of body fat but also for physiological and pathophysiological cardio-renal regulation. ${ }^{35,63}$ Elevated plasma $\mathrm{pL}$ level has been associated with hypertension in both lean and overweight/obese hypertensive patients. ${ }^{64,65}$ Leptin is likely to be involved in the pathogenesis of obesity hypertension, because it causes a significant increase in overall SNS activity, exerts a direct effect on the kidneys (resulting in increased sodium reabsorption) and regulates vasodilatation and vasoconstriction involving nitric oxidedependent and oxide-independent mechanisms. ${ }^{62,66,67}$ In this study, plasma leptin significantly decreased after weight loss in patients with greater weight reduction and normalized BMI, which is consistent with previous observations. ${ }^{68-70}$ Such a reduction in $\mathrm{pL}$ could have a role in the reducing BP values, which accompanied weight loss. We did not perform a statistical analysis to evaluate the possible relation between decreased leptin levels and insulin improvement observed in patients. This hypothetical relationship may be considered in the context of recent findings that support the direct involvement of hypothalamic leptin and insulin sensitivity in the liver, even if these results come from experimental studies in animals and need further support from studies in humans. ${ }^{71,72}$

The observed efficacy of BW loss to significantly lower BP levels and reversing some metabolic and endocrinologic parameters associated with excess BW strengthens the role of dietary intervention aimed at reducing and possibly normalizing BW as a first-line treatment of overweight, non-obese patients with uncomplicated stage 1 hypertension. Such an intervention may be effective in these patients as they are more likely to present functional, reversible vascular alterations, whereas structural, non-reversible alterations develop with the progression and persistence of excess BW.

In this study, of the 106 patients who normalized their BMI, 52 patients $(49 \%)$ were also able to normalize their BP values. Their demographic and clinic characteristics and their metabolic and endocrine parameters, both at baseline and at the end of the study, were not different from those of patients who failed to normalize their BP, despite similar BW loss. Evaluation of the relationship between BMI and DBP changes showed a strong positive correlation in both groups, although this correlation was different between the groups (Figure 1). That is, for the same degree of BMI reduction there were two degrees of BP decrease, one greater and one lower. The difference in the correlation of BP response and BMI reduction was independent of age, gender and duration of hypertension. These findings raise the provocative question as to whether it is still correct to define 'essential hypertensives' as those subjects who normalize their BP by reducing or normalizing their BMI or whether it may be more appropriate to consider that these patients are affected by a form of secondary hypertension that is particularly susceptible to the hemodynamic, metabolic and endocrine effects of excess fat.

\section{CONCLUSIONS}

The results of this study indicate that in overweight, non-obese patients with stage 1 hypertension (that is, a population in which the weight-related structural alterations of the vascular wall are not yet developed and functional changes are probably still reversible), BW reduction was effective in significantly reducing BP levels and reversing some metabolic and endocrinologic abnormalities associated with excess BW. This was more evident in patients who normalized their BMI and presented with a greater decrease in BP and in plasma insulin, aldosterone, renin and particularly leptin levels. Half of the patients who normalized their BMI also normalized their BP levels, which could be indicative of a form of hypertension strictly secondary to excess fat in these patients.

\section{CONFLICT OF INTEREST}

The authors declare no conflict of interest.

1 Burton BT, Foster WR, Hirsch J, Van Itallie TB. Health implications of obesity: an NIH Consensus Development Conference. Int J Obes 1985; 9: 155-170.

2 Sowers JR. Obesity as a cardiovascular risk factor. Am J Med 2003; 115 (8A): 37 S-41S. 
3 Williams PT, Hoffman K, La I. Weight-related increases in hypertension, hypercholesterolemia and diabetes risk in normal weight male and female runners. Arterioscler Thromb Vasc Biol 2007; 27: 1811-1819.

4 Expert panel on the identification evaluation treatment of overweight in adults. Clinical guidelines on the Identification, Evaluation and Treatment in overweight and obesity in adults: executive summary. Am J Clin Nutr 1998; 64: 899-917.

5 Lakka HM, Lakka TA, Tuomilehto J, Salonen JT. Abdominal obesity is associated with increased risk of acute coronary events in men. Eur Heart J 2002; 23: 706-713.

6 Mc Lellan F. Obesity rising to alarming levels around the world. Lancet 2002; 359: 1412

7 Bray GA. Epidemiology, risks and pathogenesis of obesity. Meat Sci 2005; 71: 2.

8 Rosamond W, Flegal K, Friday G, Furie K, Go A, Greenlund K, Haase N, Ho M, Howard V, Kissela B, Kittner S, Lloyd-Jones D, McDermott M, Meigs J, Moy C, Nichol G, O'Donnell CJ, Roger V, Rumsfeld J, Sorlie P, Steinberger J, Thom T, Wasserthiel-Smoller $\mathrm{S}$, Hong Y, American Heart Association Statistics Committee Stroke Statistics Subcommittee. Heart disease and stroke statistics-2007 update: a report from the American Heart Association Statistics Committee and Stroke Statistics Subcommittee. Circulation 2007; 115: e69-e171.

9 Ogden CL, Carroll MD, Curtin LR, McDowell MA, Tabak CJ, Flegal KM. Prevalence of overweight and obesity in the United States 1999-2004. JAMA 2006; 295: 1549-1555.

10 Must A, Spadano J, Coakley EH, Field AE, Colditz G, Dietz WH. The disease burden associated with overweight and obesity. J Am Med Assoc 1999; 282: 1523-1529.

11 Guidelines Sub-Committee. 1999 World Health Organization/International Society of Hypertension. Guidelines for the management of Hypertension. J Hypertens 2003; 21: 1011-1053.

12 Richards RJ, Thakur V, Reisin E. Obesity-related hypertension: its physiological basis and pharmacological approaches to its treatment. J Hum Hypertens 1996; 10 (Suppl 3): S59-S64.

13 Sharma AM, Engeli S, Pischon T. New developments in mechanisms of obesity-induced hypertension: role of adipose tissue. Curr Hypertebs Rep 2001; 3: 152-156.

14 Rocchini AP. Obesity hypertension. Am J Hypertens 2002; 15: 50S-52S.

15 Jonk AM, Houben AJ, de Jongh RT, Serné EH, Schaper NC, Stehouwer CD. Microvascular function in obesity: a potential mechanism in the pathogenesis of obesityassociated insulin resistance and hypertension. Physiology 2007; 22: 252-260.

16 Serné EH, de Jongh RT, Eringa EC, IJzerman RG, Stehouwer CD. Microvascular dysfunction: a potential patophysiological role in the metabolic syndrome. Hypertension 2007; 50: 204-211.

17 Stapleton PA, James ME, Goodwill AG, Frisbee JC. Obesity and vascular dysfunction. Pathophysiology 2008; 15: 79-89.

18 Reisin E, Abel R, Modan M, Silverberg DS, Eliahou HE, Modan B. Effect of weight loss without salt restriction on the reduction of blood pressure in overweight hypertensive patients. N Engl J Med 1978; 298: 1-6.

19 Dornfeld LP, Maxwell MH, Vaks AU, Schroth P, Tuck ML. Obesity and hypertension: long-term effects of weight reduction on blood pressure. Int J Obes 1985; 9: 381-389.

20 Schotte DE, Stunkard AJ. The effects of weight reduction on blood pressure in 301 obese patients. Arch Intern Med 1990; 150: 1701-1704.

21 Davis BR, Blaufox MD, Oberman A, Wassertheil-Smoller S, Zimbaldi N, Cutler JA Kirchner K, Langford HG. Reduction in long-term antihypertensive medication requirements: effects of weight reduction by dietary intervention in overweight persons with mild hypertension. Arch Intern Med 1993; 153: 1773-1782.

22 Sharma AM, Golay A. Effect of orlistat-induced weight loss on blood pressure and heart rate in obese patients with hypertension. J Hypertens 2002; 20: 1873-1878.

23 Stamler R, Stamler J, Gosch FC, Civinelli J, Fishman J, McKeever P, McDonald A, Dyer AR. Primary prevention of hypertension by nutritional-hygienic means: final report of a randomized, controlled trial. JAMA 1989; 262: 1801-1807.

24 Trials of Hypertension Prevention Collaborative Research Group. Effects of weight loss and sodium reduction intervention on blood pressure and hypertension incidence in overweight people with high-normal blood pressure: the Trials of hypertension Prevention, phase II. Arch Intern Med 1997; 157: 657-667.

$25 \mathrm{He} \mathrm{J}$, Whelton PK, Appel LJ, Charleston J, Klag MJ. Long-term effects of weight loss and dietary sodium reduction on incidence of hypertension. Hypertension 2000; 35: 544-549.

26 Moore LL, Visioni A, Qureshi M, Bradlee L, Ellison C, D'Agostino R. Weight loss in overweight adults and the long-term risk of hypertension. The Framingham Study. Arch Intern Med 2005; 165: 1298-1303.

27 Winnicki M, Bonso E, Dorigatti F, Longo D, Zaetta V, Mattarei M, D’Este D, Laurini G, Pessina AC, Palatini P. Effect of body weight loss on blood pressure after 6 years of follow-up in stage 1 hypertension. Am J Hypertens 2006; 19: 1103-1109.

28 Mancia G, De Backer G, Dominiczak A, Cifkova R, Fagard R, Germano G, Grassi G, Heagerty AM, Kjeldsen SE, Laurent S, Narkiewicz K, Ruilope L, Rynkiewicz A, Schmieder RE, Boudier HA, Zanchetti A, ESH-ESC Task Force on the Management of Arterial Hypertension. 2007 ESH-ESC Practice Guidelines for the Management of Arterial Hypertension: ESH-ESC Task Force on the Management of Arterial Hypertension. J Hypertens 2007; 25: 1751-1762.

29 National Institutes of Health. Clinical guidelines on the identification, evaluation, and treatment of overweight and obesity in adults-the evidence report. Obes Res 1998; 6 (Suppl 2): 51S-209S.

30 Derosa G, Cicero AF, Murdolo G, Piccinni MN, Fogari E, Bertone G, Ciccarelli L, Fogari R. Efficacy and safety comparative evaluation of orlistat and sibutramine treatment in hypertensive obese patients. Diabetes Obes Metab 2005; 7: 47-55.

31 Derosa G, Mugellini A, Ciccarelli L, Fogari R. Randomized, double-blind, placebocontrolled comparison of the action of orlistat, fluvastatin, or both an anthropometric measurements, blood pressure, and lipid profile in obese patients with hypercholesterolemia prescribed a standardized diet. Clin Ther 2003; 25: 1107-1122.

32 Derosa G, Mugellini A, Ciccarelli L, Rinaldi A, Fogari R. Effects of Orlistat, Simvastatin, and Orlistat+Simvastatin in obese patients with hypercholesterolemia: A randomized, open-label trial. Curr Ther Res 2002; 63: 621-633.

33 Derosa G, Cicero AF, Murdolo G, Ciccarelli L, Fogari R. Comparison of metabolic effects of orlistat and sibutramine treatment in Type 2 diabetic obese patients. Diabetes Nutr Metab 2004; 17: 222-229.

34 Nakou ES, Filippatos TD, Georgoula M, Kiortsis DN, Tselepis AD, Mikhailidis DP, Elisaf MS. The effect of orlistat and ezetimibe, alone or in combination, on serum LDL and small dense LDL cholesterol levels in overweight and obese patients with hypercholesterolaemia. Curr Med Res Opin 2008; 24: 1919-1929.

35 Heding LG. Determination of total serum insulin (IRI) in insulin-treated diabetic patients. Diabetologia 1972; 8: 260-266.

36 Misra A, Garg A. Leptin: its receptor and obesity. J Invest Med 1996; 44: 540-548.

37 Stevens VJ, Obarzanek E, Cook NR, Lee IM, Appel LJ, Smith West D, Milas NC, Mattfeldt-Beman M, Belden L, Bragg C, Millstone M, Raczynski J, Brewer A, Singh B, Cohen J, Trials for the Hypertension Prevention Research Group. Long-term weight loss and changes in blood pressure: results of the Trials of Hypertension Prevention, phase II The Hypertension Prevention Research Group. Ann Intern Med 2001; 134: $1-11$.

38 Oberman A, Wassertheil-Smoller S, Langford HG, Blaufox MD, Davis BR, Blaszkowski $\mathrm{T}$, Zimbaldi N, Hawkins CM. Pharmacologic and nutritional treatment of mild hypertensives: changes in cardiovascular risk status. Ann Intern Med 1990; 112: 89-95.

39 Langford HG, Davis BR, Blaufox D, Oberman A, Wassertheil-Smoller S, Hawkins M, Zimbaldi N. Effect of drug and diet treatment of mild hypertension on diastolic blood pressure. The TAIM Research Group. Hypertension 1991; 17: 210-217.

40 Anderssen S, Holme I, Urdal P, Hjermann I. Diet and exercise intervention have favourable effects on blood pressure in mild hypertensives: the Oslo Diet and Exercise Study (ODES). Blood Press 1995; 4: 343-349.

41 Masuo K, Mikami H, Ogihara T, Tuck ML. Different mechanisms in weight-loss induced blood pressure reduction between a low caloric diet and an aerobic exercise. J Hypertens 2002; 20 (Suppl 4): S204.

42 Staessen J, Fagard R, Amery A. The relationship between body weight and blood pressure. J Human Hypertens 1988; 2: 207-217.

43 Ebrahim D, Smith GD. Lowering blood pressure: a systematic review of sustained effects of non-pharmacological interventions. J Public Health Med 1998; 20: 441-448.

44 Neter JE, Stam BE, Kok FJ, Grobbee DE, Geleijnse JM. Influence of weight reduction on blood pressure. A meta-analysis of randomized controlled trials. Hypertension 2003; 42: 878-884.

45 Bonner G. Hyperinsulinemia, insulin resistance and hypertension. J Cardiovasc Pharmacol 1994; 24 (Suppl 2): S39-S49.

46 Osei K. Insulin resistance and systemic hypertension. Am J Cardiol 1999; 84: 33J-36J.

47 Genuth SM. Insulin secretion in obesity and diabetes: an illustrative case. Ann Intern Med 1977; 87: 714-716.

48 Tuck ML, Sowers J, Dornfield L, Kledzik G, Maxwell M. The effect of weight reduction on blood pressure, plasma renin activity and aldosterone levels in obese patients. N Engl J Med 1981; 304: 930-933.

49 Reisin E, Foohlich ED. Effect of weight reduction on arterial pressure. J Chronic Dis 1982; 35: 887-891.

50 Engeli S, Sharma AM. The renin-angiotensin system and natriuretic peptides in obesity-associated hypertension. J Mol Med 2001; 79: 20-21.

51 Rossi GP, Belfiore A, Bernini G, Fabris B, Caridi G, Ferri C, Giacchetti G, Letizia C, Maccario M, Mannelli M, Palumbo G, Patalano A, Rizzoni D, Rossi E, Pessina AC, Mantero F, Primary Aldosteronism Prevalence in hYpertension Study Investigators. Body mass index predicts plasma aldosterone concentrations in overweight-obese primary hypertensive patients. J Clin Endocrinol Metab 2008; 93 : 2566-2571.

52 Van Harmelen V, Ariapart P, Hoffstedt J, Lundkvist I, Bringman S, Arner P. Increased adipose angiotensinogen gene expression in human obesity. Obes Res 2000; 8 : 337-341.

53 Vaz M, Jennings G, Turner A, Cox H, Lambert G, Esler M. Regional sympathetic nervous activity and oxygen consumption in obese normotensive human subjects. Circulation 1997; 96: 3423-3429.

54 Rossi GP, Sticchi D, Giuliani L, Bernante P, Zavattiero S, Pessina AC, Nussdorfer GG. Adiponectin receptor expression in the human adrenal cortex and aldosterone-producing adenomas. Int J Mol Med 2006; 17: 975-980.

55 Caprio M, Feve B, Claes A, Viengchareun S, Lombes M, Zennaro MC. Pivotal role of the mineralcorticoid receptor in corticosteroid-induced adipogenesis. FASEB J 2007; 21: 2185-2194.

56 Eggena P, Sowers JR, Maxwell MH, Barrett JD, Golub MS. Hormonal correlates of weight loss associated with blood pressure reduction. Clin Exp Hypertens 1991; 13: 1447-1456.

57 Harp JB, Henry SA, Di Girolamo M. Dietary weight loss decreases serum angiotensinconverting enzyme activity in obese adults. Obes Res 2002; 10: 985-990.

58 Engeli S, Böhnke J, Gorzelniak K, Janke J, Schling P, Bader M, Luft FC, Sharma AM. Weight loss and the renin-angiotensin-aldosterone system. Hypertension 2005; 45 : 356-362.

59 Young JB, Mullen D, Landsberg L. Caloric restriction lowers blood pressure in the spontaneously hypertensive rat. Metabolism 1978; 27: 1711-1714. 
60 Jung RT, Shetty PS, Barrand M, Callingham BA, James WPT. Role of catecholamines in hypotensive response to dieting. Br Med J 1979; 1: 12-13.

61 Shuldiner AR, Yang R, Gong DW. Resistin, obesity and insulin resistance: the emerging role of the adypocyte as an endocrine organ. N Eng/ J Med 2001; 345: 1345-1346.

62 Eringa EC, Bakker W, Smulders YM, Serné EH, Yudkin JS, Stehouwer CD. Regulation of vascular function and insulin sensitivity by adipose tissue: focus on perivascular adipose tissue. Microcirculation 2007; 14: 389-402.

63 Luo JD, Zhang GS, Chen MS. Leptin and cardiovascular diseases. Timely Top Med Cardiovasc Dis 2005; 9: E34.

64 Uçkaya G, Ozata M, Sonmez A, Kinalp C, Eyileten T, Bingol N, Koc B, Kocabalkan F, Ozdemir IC. Plasma leptin levels strongly correlate with plasma renin activity in patients with essential hypertension. Horm Metab Res 1999; 31: 435-438.

65 Barba G, Russo O, Siani A, lacone R, Farinaro E, Gerardi MC, Russo P, Della Valle E, Strazzullo P. Plasma leptin and blood pressure in men: graded association independent of body mass and fat pattern. Obes Res 2003; 11: 160-166.

66 Eikelis N, Schlaich M, Aggarwal A, Kaye D, Esler M. Interactions between leptin and the human sympathetic nervous system. Hypertension 2003; 41: 1072-1079.
67 Guha PK, Villareal D, Reams GP, Freeman RH. Role of leptin in the regulation of body fluid and pressures. Am J Ther 2003; 10: 211-218.

68 Havel PJ, Kasim-Karakas S, Mueller W, Johnson PR, Gingerich RL, Stern JS. Relationship of plasma leptin to plasma insulin and adiposity in normal weight and overweight women: effects of dietary fat content and sustained weight loss. J Clin Endocrinol Metab 1996; 81: 4406-4413.

69 Reseland JE, Anderssen SA, Solvoll K, Hjermann I, Urdal P, Holme I, Drevon CA. Effect of long-term changes in diet and exercise on plasma leptin concentrations. Am J Clin Nutr 2001; 73: 240-245.

70 Itoh K, Imai K, Masuda T, Abe S, Tanaka M, Koga R, Itoh H, Matsuyama T, Nakamura $M$. Relationship between changes in serum leptin and blood pressure after weight loss. Hypertens Res 2002; 25: 881-886.

71 German J, Kim F, Schwartz GJ, Havel PJ, Rhodes CJ, Schwartz MW, Morton GJ. Hypothalamic leptin signaling regulates hepatic insulin sensitivity via a neurocircuit involving the vagus nerve. Endocrinology 2009; 150: 4502-4511.

72 Niswender KD, Schwartz MW. Insulin and leptin revisited: adiposity signals with overlapping physiological and intracellular signaling capabilities. Front Neuroendocrinol 2003; 24: 1-10. 